\title{
The formation mechanism of modified thin-film structures based on Ge-Se(S) systems and its influence on physical properties
}

\author{
G.T. Horvat ${ }^{1}$, O.S. Kondratenko ${ }^{2}$, V.Ju. Loja ${ }^{2}$, I.M. Myholynets ${ }^{1}$, I.J. Rosola ${ }^{1}$, N.V. Jurkovych ${ }^{1}$ \\ ${ }^{1}$ Uzhgorod National University, 54, Voloshyna str., 88000 Uzhgorod, Transcarpathia, Ukraine \\ E-mail: horvathalina@mail.ru \\ ${ }^{2} V$. Lashkaryov Institute of Semiconductor Physics, NAS of Ukraine \\ ${ }^{3}$ Institute of Electronic Physics, NAS of Ukraine
}

\begin{abstract}
The mechanisms of formation of modified thin-film structures based on Ge$\mathrm{Se}(\mathrm{S})$ systems with different $\mathrm{Al}, \mathrm{Bi}, \mathrm{Pb}, \mathrm{Te}$, In modifiers evaporated in vacuum have been determined. The process of their growth and the structure is greatly influenced by the vapor composition, energetic state of its particles, the velocity of condensation, the temperature of the lining and that of evaporator. The $\left\langle\mathrm{Ge}_{0.4} \mathrm{~S}_{0.6}: \mathrm{X}\right\rangle$ (Bi, $\mathrm{Pb}$,In), $\left\langle\mathrm{Ge}_{0.4} \mathrm{Se}_{0.6}: \mathrm{In}\right\rangle$ structure is characterized by the mechanism of condensation which is realized according to the type: vapor-liquid-solid phase with coalescence. The condensation mechanism in $\left\langle\mathrm{Ge}_{0.4} \mathrm{~S}_{0.6}: \mathrm{Al}(\mathrm{Te})\right\rangle$ structures is realized according to the type vapor-solid phase. The roughness of modified $\mathrm{Al}$ (2 at. \%), Bi (14 at. \%), $\mathrm{Pb}$ (12 at. \%), In ( 1 at. $\%, 5$ at. $\%)$ structures is $1 \ldots 13 \mathrm{~nm}$, and for $\left\langle\mathrm{Ge}_{0.4} \mathrm{~S}_{0.6}: \mathrm{Te}\right\rangle(\mathrm{Te}$ is 30.7 at. \%) structure reaches $\sim 37 \mathrm{~nm}$. The thickness and optical parameters of modified thin-film structures have been determined using the method of multiangular ellipsometry.
\end{abstract}

Keywords: modified thin-film structures, condensation mechanism, surface morphology, optical parameters.

Manuscript received 26.10.06; accepted for publication 26.03.07; published online 01.06.07.

\section{Introduction}

Thin films with the micron thickness may differ substantially by their properties from massive samples. It opens the opportunity to create materials, which are new both by their structure and properties. Using them, the practical realization of nanocrystalline state becomes possible. This fact is very important for thin-film electronics, optics and sensorics.

Nowadays, there exist a great number of formation methods of gradient structures with the necessary profiles of modifier distribution. These methods include thermal rectification of multicomponent alloys, different kinds of ionic evaporation, epitaxy, alloying, as well as the methods of simultaneous evaporation of components from two and more evaporators. The choice of the method to obtain gradient structures is conditioned by a specific task and available technological means. The forecast of film peculiarities is conditioned not only by its very small size, but by the correct choice of modifier element, enabling the creation of structures with the target properties. This article highlights the mechanisms of formation of modified thin-film structures based on
$\mathrm{Ge}-\mathrm{Se}(\mathrm{S})$ systems with different modifiers as well as their influence on physical properties.

\section{The regularities of film evaporation and condensation}

While analysing the process of surface coating formation on lining one should single out two aspects: the physical and technological ones [1]. The physical aspect consists of formation regularities of initial surface layers, the character of longitudinal and transverse structures, surface relief, etc. The process of condensation and the structure of the film formed depend upon the kinetic parameters of condensation, temperature and the potential relief of the lining, the density of the falling molecular beam, the character of evaporating atoms interaction. The most important is the temperature of the lining. The molecular beam condenses on it in the case when the temperature of the lining is lower than some critical one.

As far as the technological aspect is concerned, two mechanisms of condensation are realized: vapor-solid phase and vapor-liquid-solid phase [1]. These conden- 
sation mechanisms determine different ways of film formation and their growth from the vapor phase, influencing the film properties. It is necessary to mention that the mechanism of condensation depends upon the correlation of temperature of lining and that of melting, at which the substance being condensed. With the change of lining temperature, it is possible to change the mechanism of condensation. With the condensation of molecular beams of complex composition, the mechanism of condensation depends on the composition of vapor phase as well. After finishing the formation of the whole layer, the regularities of the film growth are determined not only by the mechanism of substance condensation, but mainly by the structure of the initially formed layers.

In the process of obtaining the gradient films on the basis of glass-like $\mathrm{Ge}_{0.4} \mathrm{Se}(\mathrm{S})_{0.6}$ with $\mathrm{Al}, \mathrm{Bi}, \mathrm{Pb}, \mathrm{Te}$, In modifiers the method of thermal evaporation in vacuum from two separate evaporators has been used [2]. The necessary flow of the modifying component has been created due to the change of evaporation temperature. The control of chemical and quantitative composition of gradient films being obtained has been conducted by the method of mass spectrometry of post-ionized neutral particles. The thickness of films was from 0.45 to $2.7 \mathrm{~nm}$.

\section{The investigation of film surface}

The investigation of microrelief peculiarities of gradient films has been performed using an atomic force microscope (AFM) Dimension ${ }^{\mathrm{TM}}$ 3000. The measurements have been made in air at the room temperature using the nib made of silicon; with radius of curvature $\sim 5-10 \mathrm{~nm}$ on a string console element with the coefficient of rigidity $0.01-0.6 \mathrm{~N} / \mathrm{m}$. The geometry of the nib and its interaction with the surface under investigation limited the resolution of horizontal dimension to $2 \mathrm{~nm}$ and of vertical ones to $0.1 \mathrm{~nm}$ [3].

Figs. 1-3 depict the morphology of the surfaces of $\left\langle\mathrm{Ge}_{0.4} \mathrm{Se}(\mathrm{S})_{0.6}: \mathrm{In}\right\rangle$ heterogeneous films. It is complicated enough and depends upon the type of matrix and the type of the modifier that was introduced.

It has been found that while doping with $\mathrm{Bi}, \mathrm{Pb}$, In modifiers the formation of condensate is carried out according to the type vapor-liquid-solid phase with coalescence. Condensed atoms interact between themselves stronger than with the surface of the neutral lining. This is the explanation of their free and intensive migration along the surface. With the high density of the flow of the substance being evaporated, the nuclei of crystal or liquid phase are formed. The surface of the structure with such a mechanism of condensation is characterized by the formation of canals and merging small islands into the larger ones. Table 1 demonstrates the basic parameters that characterize the surface of the films. The height of the outgrowth of $\mathrm{Bi}$ gradient structure varies from 0.4 to $2.5 \mathrm{~nm}$, while that for $\mathrm{Pb}$ gradient structures varies from 1.2 to $5.4 \mathrm{~nm}$ [4].

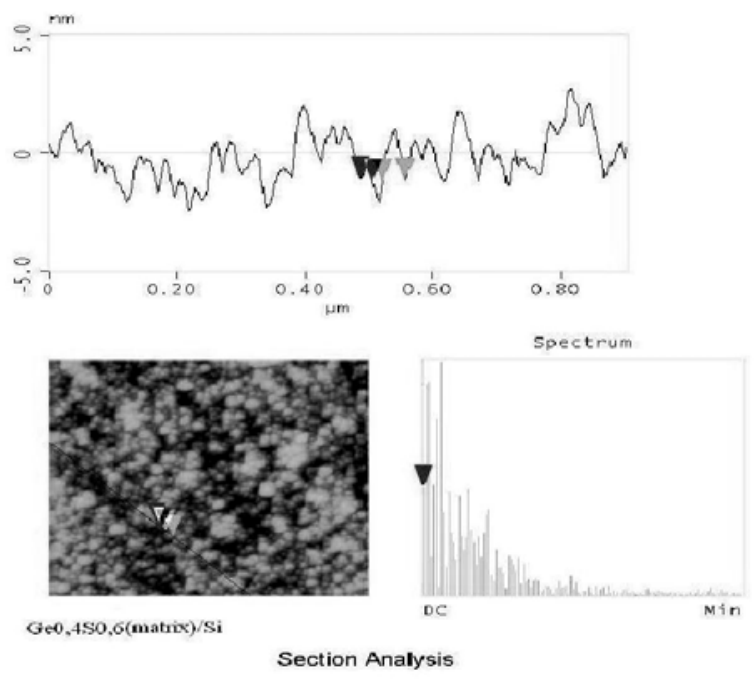

Fig. 1. Section analysis of $\mathrm{Ge}_{0.4} \mathrm{~S}_{0.6}:$ In gradient film surface.

It has been found that the increase of the In concentration (from 1 to 5 at. \%) in Se-based structure does not lead to significant changes in surface morphology. The roughness of their surfaces approximates the one of the very matrix (about $0.5 \mathrm{~nm}$ ). The height of the roughness is: $0.5 \ldots 1.3 \mathrm{~nm}$ when $\mathrm{In}$ is 1 at. $\%$ and $0.5 \ldots 2.13 \mathrm{~nm}$ when $\mathrm{In}$ is 5 at. $\%$.

$\left\langle\mathrm{Ge}_{0.4} \mathrm{~S}_{0.6}: \mathrm{In}\right\rangle$ (5 at. \% In) film is characterized by the vapor-liquid-solid phase type of condensation. But in contrast to the chaoticity of island structure of the Se film surface (Fig. 2), it is characterized by the partial inputting of comparatively big islands (Fig. 3). The height of unevenness of the gradient structure surface varies from 0.8 to $13.6 \mathrm{~nm}$.

When the forces of interaction between substance molecules being condensed are less than the forces of their bonds with the lining, the influence of kinetic parameters of the lining on the process of film formation according to the vapor-solid phase mechanism rises

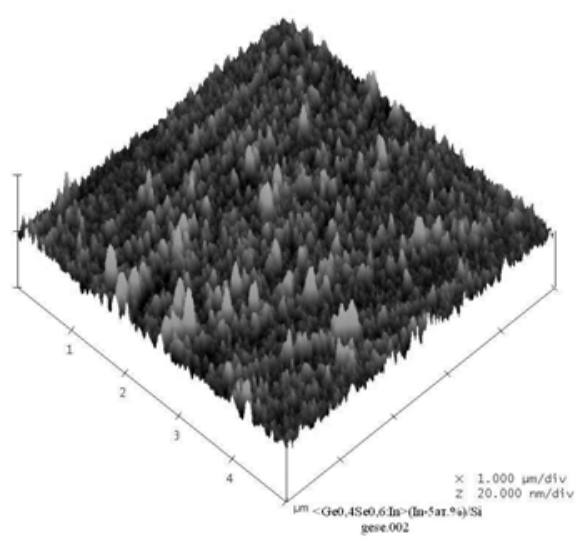

Fig. 2. Morphology of the gradient film $\mathrm{Ge}_{0.4} \mathrm{~S}_{0.6}$ surface. 
sharply. Such a mechanism of condensation of the substance being evaporated is characteristic of $\left\langle\mathrm{Ge}_{0.4} \mathrm{~S}_{0.6}: \mathrm{X}\right\rangle\left(\mathrm{X}\right.$ is Te, $\mathrm{Al}$ ) films. For $\left\langle\mathrm{Ge}_{0.4} \mathrm{~S}_{0.6}: \mathrm{Al}\right\rangle$ ( $\mathrm{Al}$ is 2 at.\%) structure, it has been established that the condensate formation is carried out accompanied by dense filling with islands of smaller sizes $(1.2 \ldots 5.4 \mathrm{~nm})$. This process is not observed in structures with $\mathrm{In}, \mathrm{Bi}, \mathrm{Pb}$ modifiers. In contrast to former results for $\left\langle\mathrm{Ge}_{0.4} \mathrm{~S}_{0.6}: \mathrm{Te}\right\rangle$ (Te is 30.7 at. \%) film, parameters characterizing the roughness value differ considerably. Such a difference in value for the structures with $\mathrm{Te}$ is explained by the availability of two chalcogenides with two different parameters. Due to this fact, the intersubstitution of $S$ by $\mathrm{Te}$ is possible. It leads to the partial disordering of the amorphous matrix framework based on glass-like $\mathrm{Ge}_{0.4} \mathrm{~S}_{0.6}$, to formation of solid solutions with the target concentrations according to the vapor-solid phase mechanism of condensates with the formation of a considerable number of large islands. The island height reaches $37 \mathrm{~nm}$. As it is seen from the figures, the surface roughness of the films under investigation is insufficient, and varies within the limits of 1 to $13 \mathrm{~nm}$ when the structure thickness is between 500 to $3000 \mathrm{~nm}$. Only in the case of Te the roughness thickness reaches $37 \mathrm{~nm}$, which means that the surfaces of films are smooth enough.

The main peculiarity of obtaining the amorphous gradient structures with the modifiers in a solid phase lies in the fact that they are always formed under unbalanced conditions, when the maximum of potential energy of the system is not reached. High energy of amorphous state influences first of all the ways of packing the structural units of solid substance, which are numerous in this case.

Table 1. Basic parameters characterizing film surfaces.

\begin{tabular}{|c|c|c|c|c|}
\hline Composition & $\begin{array}{c}R_{\mathrm{MS}} \\
\text { (mean } \\
\text { vertical } \\
\text { quadratic } \\
\text { devia- } \\
\text { tion), nm }\end{array}$ & $\begin{array}{c}R_{a} \text { (mean } \\
\text { arithme- } \\
\text { tical } \\
\text { deviation), } \\
\text { nm }\end{array}$ & $\begin{array}{c}R_{\mathrm{max}} \\
\text { (maxi- } \\
\text { mum } \\
\text { devia- } \\
\text { tion), nm }\end{array}$ & $\begin{array}{c}\text { Uneven- } \\
\text { ness } \\
\text { height, } \\
\text { nm }\end{array}$ \\
\hline $\mathrm{Ge}_{0.4} \mathrm{~S}_{0.6}$ & 0.67 & 0.5 & 2.40 & $0.3-0.5$ \\
\hline $\begin{array}{c}\left\langle\mathrm{Ge}_{0.4} \mathrm{~S}_{0.6}: \mathrm{Bi}\right\rangle \\
(14 \text { at.\%) }\end{array}$ & 0.80 & 0.22 & 3.34 & $0.4-2.5$ \\
\hline $\begin{array}{c}\left\langle\mathrm{Ge}_{0.4} \mathrm{~S}_{0.6}: \mathrm{Te}\right\rangle \\
(30 \text { at.\%) }\end{array}$ & 6.93 & 5.45 & 21.84 & $2.3-36.9$ \\
\hline $\begin{array}{c}\left\langle\mathrm{Ge}_{0.4} \mathrm{~S}_{0.6}: \mathrm{Al}\right\rangle \\
(2 \text { at.\%) }\end{array}$ & 1.53 & 1.03 & 8.07 & $1.4-6.3$ \\
\hline $\begin{array}{c}\left\langle\mathrm{Ge}_{0.4} \mathrm{~S}_{0.6}: \mathrm{Pb}\right\rangle \\
(12 \text { at.\%) }\end{array}$ & 2.44 & 2.06 & 11.06 & $1.2-5.4$ \\
\hline $\begin{array}{c}\left\langle\mathrm{Ge}_{0.4} \mathrm{~S}_{0.6}: \mathrm{In}\right\rangle \\
(5 \text { at.\%) }\end{array}$ & 3.23 & 2.41 & 8.83 & $0.8-13.6$ \\
\hline $\mathrm{Ge}_{0.4} \mathrm{Se} \mathrm{e}_{0.6}$ & 1.78 & 0.26 & 1.06 & $0.2-0.5$ \\
\hline $\begin{array}{c}\left\langle\mathrm{Ge}_{0.4} \mathrm{Se}_{0.6}: \mathrm{In}\right\rangle \\
(1 \text { at.\%) }\end{array}$ & 2.26 & 0.7 & 2.93 & $0.5-1.3$ \\
\hline $\begin{array}{c}\left\langle\mathrm{Ge}_{0.4} \mathrm{Se}_{0.6}: \mathrm{In}\right\rangle \\
(5 \text { at.\%) }\end{array}$ & 0.72 & 0.59 & 2.29 & $0.5-2.13$ \\
\hline
\end{tabular}

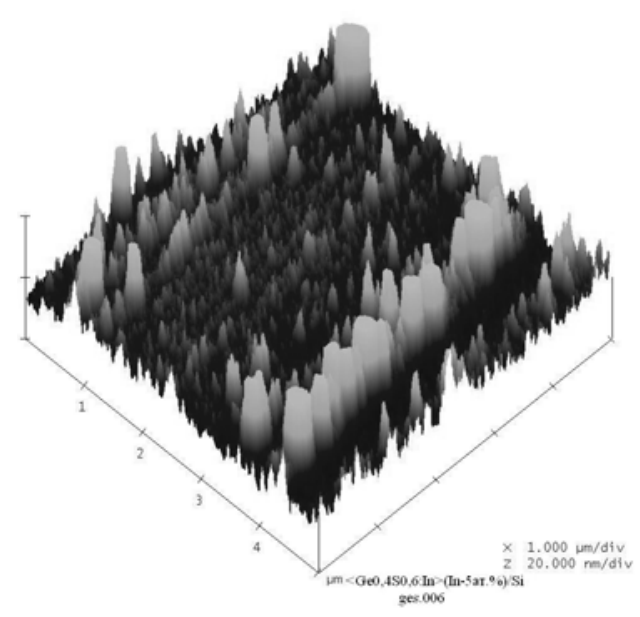

Fig. 3. Morphology of the gradient film $\left\langle\mathrm{Ge}_{0.4} \mathrm{~S}_{0.6}: \mathrm{In}\right\rangle$ (5 at. $\%$ In) surface.

One of the most perspective methods of thin films investigation, which helps to obtain information concerning the purity of the surface and the heterogeneity of the structure, is ellipsometry. Its methods are contactless, not influencing the properties and allow to define both the optical contacts and film thickness. The procedure of ellipsometry is based on working out the direct and reversed problems of ellipsometry. The measured ellipsometric angles for a given structure with the known optical peculiarities and geometric sizes are calculated within the limits of the direct problem. The reversed problem uses angles $\Delta$ and $\Psi$, measured using an ellipsometer to reveal unknown optical parameters of the system under investigation [5]. Multiangular ellipsometric measurements have been carried out according to a null procedure on the basis of the ellipsometer ЛЭФ-3M-1 [6]. The working wavelength $(\lambda)$ is equivalent to $632.8 \mathrm{~nm}$ and the angular range of light incidence $(\varphi)$ is equivalent to $45-80^{\circ}$.

Having used angles $\Delta$ and $\Psi$ measured using the ellipsometer in order to find unknown optical parameters of the system under investigation, the optical parameters of films have been calculated (Table 2).

Table 2. Optical parameters of films $(\lambda=0.6328 \mu \mathrm{m})$.

\begin{tabular}{|c|c|c|c|}
\hline Composition & $\begin{array}{c}\text { Refraction } \\
\text { index, } \\
n\end{array}$ & $\begin{array}{c}\text { Reflection } \\
\text { coefficient, } \\
k\end{array}$ & $\begin{array}{c}\text { Film } \\
\text { thickness } \\
d, \mathrm{~nm}\end{array}$ \\
\hline $\mathrm{Ge}_{0.4} \mathrm{~S}_{0.6}$ & 2.131 & 0.011 & 1000.04 \\
\hline $\begin{array}{c}\left\langle\mathrm{Ge}_{0.4} \mathrm{~S}_{0.6}: \mathrm{In}\right\rangle \\
(5 \text { at.\%) }\end{array}$ & 2.429 & 0.011 & 1001.49 \\
\hline $\begin{array}{c}\left\langle\mathrm{Ge}_{0.4} \mathrm{Se}_{0.6}: \mathrm{In}\right\rangle \\
(1 \mathrm{at} . \%)\end{array}$ & 2.361 & 0.028 & 1147.66 \\
\hline $\begin{array}{c}\left\langle\mathrm{Ge}_{0.4} \mathrm{Se}_{0.6}: \mathrm{In}\right\rangle \\
(5 \text { at.\%) }\end{array}$ & 2.350 & 0.013 & 999.98 \\
\hline \multicolumn{2}{|c|}{}
\end{tabular}


As it is seen from the table, inputting the modifier into the matrix $\mathrm{Ge}_{0.4} \mathrm{~S}_{0.6}$ leads to the increase of the refraction index, while to $\mathrm{Ge}_{0.4} \mathrm{Se}_{0.6}$ matrix to its decrease. Thicknesses of films calculated applying the ellipsometric method almost coincide with those targeted beforehand during evaporating. High accuracy of the ellipsometric method is connected with the fact that the state of light polarization reacts greatly even on/at very slight changes of the state of reflecting surface that is on the availability of different intermediate layers, preconditioned by the interaction of the surface with the environment weather or other inner processes.

\section{Conclusions}

As one can see from what has been written above, the process of growth and the structure of amorphous condensates of heterogeneous modified structures, being evaporated in vacuum, is greatly influenced by the vapor composition, energetic state of its particles, the velocity of condensation, temperature of the lining and that of evaporator. Having analyzed the results of the investigation of the surface morphology of $\left\langle\mathrm{Ge}_{0.4} \mathrm{Se}(\mathrm{S})_{0.6}: \mathrm{X}\right\rangle(\mathrm{X}-\mathrm{Al}, \mathrm{Bi}, \mathrm{Pb}, \mathrm{Te}, \mathrm{In})$ structures, the mechanisms of their formation have been established. The structure $\left\langle\mathrm{Ge}_{0.4} \mathrm{~S}_{0.6}: \mathrm{X}\right\rangle(\mathrm{Bi}, \mathrm{Pb}, \mathrm{In}),\left\langle\mathrm{Ge}_{0.4} \mathrm{Se}_{0.6}: \mathrm{In}\right\rangle$ is characterized by the mechanism of condensation which is carried out according to the type: vapor-liquid-solid phase with coalescence. The increase of the In concentration does not change significantly the surface morphology of the structure based on S, partial ordering of insular surface structure is carried out. Further investigation of the given structures with other In contents in them is of great interest. The condensation mechanism in $\left\langle\mathrm{Ge}_{0.4} \mathrm{~S}_{0.6}: \mathrm{Al}(\mathrm{Te})\right\rangle$ structures is realized according to the vapor-solid phase type. The roughness of modified $\mathrm{Al}$ (2 at.\%), Bi (14 at. \%), Pb (12 at. \%), $\operatorname{In}(1$ at. $\%, 5$ at. $\%)$ structures is $1 \ldots 13 \mathrm{~nm}$, and for $\left\langle\mathrm{Ge}_{0.4} \mathrm{~S}_{0.6}: \mathrm{Te}\right\rangle(\mathrm{Te}$ is 30.7 at. \%) structure reaches $\sim 37 \mathrm{~nm}$.
The thickness and optical parameters of modified thinfilm structures have been determined by the method of multiangular ellipsometry.

\section{Acknowledgments}

The authors express their sincere gratitude to O.S. Lytvyn for her assistance in investigations of the structures by using AFM.

\section{References}

1. Yu.M. Tairov, V.F. Tsvetkov, Technology of semiconductor and dielectric materials. Vysshaya shkola, Moscow, 1990 (in Russian).

2. N.V. Yurkovich, A.V. Lada, V.Yu. Loya, I.M. Migolinets, S.S. Krafchik, O.I. Pagulich, Peculiarities of obtaining inhomogeneous structures $\mathrm{Ge}_{2} \mathrm{~S}_{3}+\mathrm{Al}$ $(\mathrm{Bi}, \mathrm{Pb}, \mathrm{Te})$ with a preliminary set of component distribution // Collection of reports of the 14-th Intern. Symposium "Thin films in optics and electronics". - Kharkov, Published by Kharkov Physico-Technical Institute, 2002, p. 138-139 (in Russian).

3. Nanoscope. Command reference manual. - Digital Instruments, Santa Barbara, CA, 1999.

4. N.V. Yurkovich, Modelling and physical properties of modified structures based on vitreous germanium chalcogenides. Author's abstract of the candidate degree thesis (Phys.-math. sci.), Uzhgorod, 2004 (in Russian).

5. L.A. Zabashta, Investigations of optical properties of structures semiconductor - surface phase by using the method of multiangular ellipsometry. Author's abstract of the candidate degree thesis (Phys.-math. sci.), Sumy, 1996 (in Russian).

6. I.A. Shaikevich, P.I. Drozd, L.V. Poperenko, A small-size goniometer-ellipsometer and its application to studies of rough surface // Zavodskaya laboratoriya No 7, p. 35-36 (1985) (in Russian). 